\title{
LITERACIDAD VISUAL Y CRÍTICA EN ELE PARA FINES ESPECÍFICOS: LECTURA DE ANUNCIOS PUBLICITARIOS COMO PRÁCTICA SOCIAL Y POLITICA
}

\author{
CRITICAL VISUAL LITERACY IN SFL FOR \\ SPECIFIC PORPOSES: READING ADVERTISING \\ AS A SOCIAL POLITICAL PRACTICE
}

\section{Hiran Nogueira Moreira* Glauber Lima Moreira*****}

\section{RESUMEN}

Con los estudios de las multiliteracidades y de la literacidad crítica, se supera el concepto de lectura exclusivamente como decodificación, transcripción de datos y búsqueda de las intenciones del autor, es decir, se entiende que leer es una práctica crítica, social y política. De ahí, el objetivo del estudio es proponer una actividad de lectura de anuncios publicitarios en español/LE fundamentada en la perspectiva de la literacidad crítica de Cervetti et al (2001) y de la literacidad visual de Muffoletto (2001), para estudiantes de las carreras de Turismo, Publicidad, Periodismo y Comunicación Social. Analizamos cinco anuncios publicitarios de cerveza y gaseosa, además de presentar una propuesta de actividad de lectura. El objetivo de la actividad es desarrollar en el estudiante la conciencia crítica e invitarlo a transformar la realidad de opresión encontrada en su lectura. Así, el trabajo muestra que enseñar lengua extranjera es ir más allá de los contenidos gramaticales descontextualizados y puramente normativistas.

Palabras clave: literacidad visual y crítica; anuncio publicitario; enseñanza de ELE.

\section{ABSTRACT}

After the arisen and development of multiliteracies and critical literacy, it was overcome the concept of reading exclusively as decoding, transcription and search of the author's intentions, that is, it is understood that reading is a critical, social and political practice. Based on this assumption, this study aims at proposing a reading activity of advertisements in Spanish as a foreign language based on the critical literacy perspective of Cervetti et al (2001) and on the visual literacy of Muffoletto (2001) for undergraduates of Tourism,

\footnotetext{
* Instituto Federal de Educación, Ciencia y Tecnología de Ceará, IFCE, Fortaleza, CE, Brasil. hiran. nogueira@ifce.edu.br

Orcid: https://orcid.org/0000-0001-6227-4275

** Universidade Federal do Piauí, UFPI, Teresina, PI, Brasil. glauberlimamoreira@gmail.com

*** Universidade Federal do Delta do Parnaíba, UFDPar, Parnaíba, PI, Brasil.

Orcid: https://orcid.org/0000-0002-5822-4010
} 
Journalism and Social Communication. Five beer and soda advertisements were analyzed, as well as a proposal activity for reading. The objective of the activity is to develop in the student the critical awareness and to invite him to transform the reality of oppression found in his lectures. This study shows that teaching a foreign language is to go beyond the decontextualized and purely normative grammar contents.

Keywords: visual and critical literacy; advertisement; teaching of Spanish as a foreign language

\section{INTRODUCCIÓN}

La actividad lectora de anuncios publicitarios que presentamos aquí tiene como base la literacidad crítica de Cervetti et al. (2001) y la literacidad visual de Muffoletto (2001). Ésta está pensada para trabajar la lectura en la asignatura de español como lengua extranjera para Fines Específicos con estudiantes de las carreras ${ }^{1}$ de Turismo, Publicidad, Periodismo y Comunicación Social. Por medio de esta acción consideramos que se puede superar el concepto de lectura exclusivamente como decodificación, transcripción de datos y búsqueda de las intenciones del autor. No se niegan dichas acciones, pero entendemos que leer es, a su vez, una práctica crítica, social y política. Lo que supone un punto interesante para practicar con alumnos que en su futuro trabajo van a leer textos de las esferas tanto comercial como económica.

Ofrecemos el análisis de cinco anuncios publicitarios de cerveza y gaseosa, además de una propuesta de actividad de lectura. El análisis de los anuncios tiene el objetivo de ofrecer un apoyo al lector de este artículo que quizás quiera trabajar la propuesta aquí presentada. Y para que la comprensión del análisis no resulte una ardua tarea, buscamos ofrecer una fundamentación teórica que sirva de base para quienes aún no conocen la semiótica social, la multimodalidad, la literacidad crítica y visual.

Los anuncios analizados y ofrecidos para la actividad contemplan productos utilizados en el mundo de la recreación y de los jóvenes, público a quien se destina la actividad propuesta, además que no se concibe trabajar con lectura contemplando solamente el modo verbal. Actualmente, el mundo es multimodal y la academia no puede desconocer esta realidad. Nuestros estudiantes no leen únicamente palabras, sino también imágenes, gestos, colores, símbolos y cuerpos.

1. Proponemos este grupo de carreras por considerarlas cercanas al tema de la publicidad y de la recreación. Sin embargo, el lector puede adaptar nuestra propuesta para otros grupos de estudiantes. 


\section{SEMIÓTICA SOCIAL}

Al escribir sobre semiótica social, tanto Kress y van Leeuwen (2006) como van Leeuwen (2011) presentan una breve historia de las tres grandes escuelas semióticas de Occidente para llegar a explicar lo que tienen en común y en qué se diferencia la semiótica social de los otros dos tipos.

La primera escuela es la de Praga (1930-1940), desarrollada a partir del Formalismo ruso, de donde tomó sus conceptos lingüísticos para aplicarlos en el análisis de las artes visuales, el teatro y el cine. La Escuela de París (1960-1970) es la segunda. Ésta utiliza los conceptos lingüísticos de Ferdinand de Saussure y Charles Sanders Peirce para analizar la moda, el cine, la música, la fotografía, la pintura y la publicidad de la imagen, lo que pone de relieve la obra de Roland Barthes. La tercera escuela es la semiótica social emergente a partir de la década de 1990 en Australia bajo la influencia de la lingüística sistémico-funcional de Halliday y de la semiótica visual de O’Toole, Kress y van Leeuwen, por ejemplo.

Las tres escuelas semióticas citadas anteriormente tienen dos puntos en común: $1^{\circ}$. Según Almeida (2009), tales tradiciones semióticas buscan traer conceptos lingüísticos al alcance de formas no verbales como la imagen y la música; $2^{\circ}$. El uso de la noción de signo en sus trabajos.

Sin embargo, es en la noción de signo donde radica la principal diferencia entre las dos primeras escuelas y la semiótica social, pues la dimensión social del lenguaje interfiriendo en la producción del signo (sign-making), idea heredada de Halliday (1978), tiene en cuenta la forma de concebir el signo de la tercera escuela y, por tanto, está relacionada con la producción del signo. Mientras que las otras dos escuelas entienden el signo como algo objetivo y aislado de la realidad del productor, omitiendo de la subjetividad del productor del signo (sign-maker).

De acuerdo con Hodge y Kress (1988), la semiótica es "el estudio general de la semiosis, es decir, de los procesos y efectos de la producción y la reproducción, la recepción y direcciones del tráfico de todas las formas utilizadas por todos los tipos de agentes de comunicación" (HODGE; KRESS, 1988, p. 261).

Kress al afirmar que estudia los procesos y los efectos de la producción y la reproducción, la recepción y la circulación de sentidos ${ }^{2}$, se verifica la existencia de un contexto social en el que están inmersos tales procesos, efectos y agentes de

2. Cuando se trate de Multimodalidad y de Semiótica Social, nosotros preferimos la palabra "sentido" en lugar de "significado", puesto que en algunos artículos vinculados a estas áreas, hemos visto que "sentido" aparece con más frecuencia en la traducción de "meaning". 
comunicación, ya que no hay manera de entender estos procesos sin la existencia de una dimensión social.

Aunque se empiece a partir del concepto de signo definido por Saussure (1972), como un ente formado por el significado y el significante, la semiótica social no concuerda con Saussure cuando él entiende que el vínculo de significación entre el significado y el significante es arbitrario, pues así se anula la idea de que el signo es motivado y, por consiguiente, la influencia de la dimensión social:

\begin{abstract}
Se sigue que podemos ver los signos como motivados - no arbitrarios - conjunciones de significantes (formas) y significados (sentidos). En nuestra visión signos nunca son arbitrarios, y "motivación" debería ser formulada en relación con el productor de signo y al contexto en que el signo es producido, y no de forma aislada a partir del acto de producir analogías y clasificaciones. Los productores de signo utilizan las formas que ellos consideran adecuadas para la expresión de sus sentidos, en cualquier medio en que pueden producir signos. (KRESS, VAN LEEUWEN, 2006, p. 8). ${ }^{3}$
\end{abstract}

Podemos afirmar que, según la declaración anterior de Kress y van Leeuwen (2006) a favor del signo motivado, encontramos la presencia del sujeto productor del signo que tiene intereses, es decir, es un ser dotado de poder, capaz de asignar significado al signo, utilizando los modos semióticos disponibles y que más le convengan con el fin de atender sus propios intereses de representación y comunicación. Este sujeto es aquel que está involucrado en la producción, reproducción, recepción y circulación de significados, que ora es productor, ora es agente de la comunicación.

Se subraya en la citación anterior otra característica de la semiótica social: el interés del productor del signo (sign-maker). Dicho interés no es un elemento particular de aquellos que producen el signo, no es un organismo neutral, sino que revela la posición social del productor en el mundo, como afirma Kress (2010, p. 70):

Podemos decir que el interés en el momento de la producción del signo proviene de la posición del productor del signo en el mundo; Se da forma a la atención que se ajusta a una parte del mundo y actúa como un principio para la selección de significativa apropiada. ${ }^{4}$ (Énfasis añadido)

3. "It follows that we see signs as motivated - not arbitrary - conjunctions of signifiers (forms) and signifieds (meanings). In our view signs are never arbitrary, and 'motivation' should be formulated in relation to the sign - maker and the context in which the sign is produced, and not in isolation from the act of producing analogies and classifications. Sign-makers use the forms they consider apt for the expression of their meaning, in any medium in which they can make signs." (Todas las traducciones de inglés al español en este trabajo son del autor de este capítulo.)

4. "We can say that interest at the moment of sign-making arises out of sign-maker's position in the world; It shapes attention. That frames a part of the world and acts as a principle for the selection of apt signifiers." 
Kress (2010) establece que el interés del productor se ajusta a una parte del mundo y actúa como un principio para la selección de significantes entre varios, como el productor elige el más importante y desprecia a los demás; por consiguiente, no produce un signo que representa toda la realidad. Nos encontramos ahí con la idea de parcialidad de la representación en la semiótica social. Kress (2010, p. 71) explica este sesgo como sigue:

En el momento de la elaboración del signo, la representación es siempre parcial, pero también es siempre 'plena', 'completa'. Ella es parcial con respecto al objeto o fenómeno representado, ella es plena con respecto al interés del productor de signo en el momento de producirlo. Interés produce atención. Atención delimita el mundo a ser representado. La analogía traduce el interés y selecciona lo que va a ser representado como significado a través de un medio adecuado para que lo represente, el significante. El resultado es un signo formado a partir de relación de analogía. El resultado de este proceso es una metáfora. Todos los signos son metáforas, siempre nuevos, donde reposa el interés, metáforas que materializan y muestran el interés del productor signo. ${ }^{5}$ (Énfasis añadido)

Por eso podemos comprender por qué es posible que existan varias interpretaciones y opiniones sobre determinada imagen, pues, por ser parcial, no será posible ofrecer algo pleno de sentido para los entes involucrados en la comunicación. Se plantearán dudas y cuestionamientos sobre lo que ésta quiere representar, además de que el ambiente social del productor del signo puede ser completamente diferente del ámbito del receptor del signo.

Como es posible percibir, la semiótica social no se preocupa por el signo en sí, sino por el sentido que se origina en la dimensión social. Kress (2010, p. 54) hace hincapié en lo que es el propósito de la semiótica social y destaca lo social como una marca constitutiva de los procesos y efectos de la producción y la reproducción, la recepción y la circulación de los sentidos:

La teoría semiótica social está interesada en el sentido en todas sus formas. El sentido surge en ambientes sociales y en las interacciones sociales. Esto hace que la dimensión social sea la fuente, el origen y el generador de sentido. En esta teoría, "lo social" es generador de sentido, de procesos y formas semióticas, por lo tanto, la teoría es una semiótica social. ${ }^{6}$

5. "At the moment of the making of the sign, representation is always partial; yet it is always ' full', 'complete'. It is partial in relation to the object or phenomenon represented; it is full in relation to the sign-maker's interest at the moment of making the sign. Interest produces attention. Attention frames the world to be represented. Analogy translates interest and selects what is to be represented as the signified into apt means of representing it, the signifier. The result is a sign, formed on the basis of the relation of analogy. The outcome of that process is a metaphor. All signs are metaphors, always newly made, resting on, materializing and displaying the interest of the maker of the sign."

6. "Social-semiotic theory is interested in meaning, in all its forms. Meaning arises in social environments and in social interactions. That makes the social into the source, the origin and the generator of meaning. In theory here, 'the social' is generative of meaning, of semiotic processes and forms, hence the theory is a social-semiotic one" 
Estos supuestos teóricos de la semiótica social constituyen las referencias pertinentes que sustentan la multimodalidad y serán discutidos en la sección siguiente como un campo de estudio que examina cómo los signos semióticos se producen y son comprendidos en las interacciones sociales.

\section{MULTIMODALIDAD}

El término técnico "multimodal" no se originó con Kress yvan Leeuwen (2006), como puede pensarse a partir de la difusión significativa de la gramática visual desarrollada por estos dos investigadores, situación vivida principalmente en el contexto brasileño donde la mayoría de los trabajos sobre multimodalidad aún se limitan a la aplicación y el análisis de los conceptos de esa gramática.

El investigador van Leeuwen (2011) da una visión general de cómo surgió el término técnico hasta los días actuales. Para él, en los años 1920, multimodalidad aparece como término relativamente nuevo en el campo de la psicología de la percepción (Cf. DEL RÍO PEREDA, 1996; OVIEDO, 2004) para referirse a los diferentes efectos de las percepciones sensoriales. La percepción fue concebida como multimodal, puesto que integra las informaciones recibidas de los diversos sentidos del cuerpo humano.

Aún con referencia a la década de 1920, van Leeuwen dice que es en esta ocasión que la comunicación pública ${ }^{7}$ ha empezado a utilizar los recursos multimodales cada vez más, lo que influirá en las tres principales escuelas semióticas de Occidente, mencionadas anteriormente, empiezan a darse cuenta de cómo otros modos de comunicación, además de los verbales, conforman el escenario semiótico.

Aunque estas tres escuelas semióticas trabajen con una gama de modos semióticos, además del verbal, es la semiótica social la que retoma el término multimodalidad de la psicología de la percepción (HALLIDAY, 1978; KRESS, 2005, 2006). El investigador van Leeuwen (2011, p. 669) es enfático al afirmar que la semiótica social "adoptó y amplió el término <multimodalidad y lo introdujo en la lingüística aplicada y, especialmente, en el estudio del lenguaje y de la literacidad."

En este sentido, entendemos mejor que la multimodalidad como un campo de estudio (VAN LEEUWEN, 2010) es "un campo de trabajo, un dominio de investigación, una descripción del espacio y de los recursos que entran en juego

7. Van Leeuwen habla de los cambios en la televisión, el cine y las publicaciones gráficas tales como libros y revistas que se vuelven más presentes desde la década de 1920. 
en el proceso de producción del sentido" ${ }^{\prime \prime}$ (KRESS 2011, p. 242). La semiótica social encuentra en la multimodalidad su campo de aplicación, es decir, la semiótica social funciona como referencial teórico para fundamentar consistentemente el estudio y la descripción de la producción de los sentidos socialmente situados, que se producen a través del uso de los diversos modos semióticos en la perspectiva de la multimodalidad. ${ }^{9}$

Se habla en diferentes modos semióticos porque es posible percibir que la producción de sentidos mediante la interrelación de los diversos modos es una característica central para la multimodalidad. Es lo que sostiene Kress (2011, p. 42) al afirmar que:

Hay un punto fuerte para la multimodalidad como tal, es decir, la afirmación de que "lengua" es sólo uno de los varios recursos para producir sentido y que todos estos recursos disponibles en un grupo social y sus culturas en un momento particular deben ser considerados como un dominio coherente y un campo integral de recursos. Sin embargo, tales recursos son distintos para producir sentido, pero iguales potencialmente, en sus capacidades de contribuir en la producción de sentido hacia una entidad semiótica compleja, un texto o un texto como entidad. ${ }^{10}$

Lo que Kress (2011) señala no es la anulación del modo verbal (que, en la cita anterior, él llama de lengua) o descalificación, sino la relevancia de otros modos semióticos para la producción de sentido junto al modo verbal. El propio término multimodalidad subraya la importancia de la diversidad de modos.

No podemos pensar que sólo ahora el "paisaje semiótico"11 se ha convertido en multimodal, como la propia historia humana, a partir de los hombres de las cavernas, pasando por los manuscritos medievales y el arte de vanguardia, se ha caracterizado por el uso de diversos modos semióticos. El discurso, por ejemplo, está acompañado de los gestos, la escritura hace uso de tipografías variadas, diseños y colores, además de las imágenes que se relacionan con los textos escritos

8. "A field of work, a domain for enquiry, a description of the space and the resources which enter into meaning, in some way or another."

9. A pesar de que se pone de relieve el papel de la semiótica social en la multimodalidad, existen otros enfoques y teorías que se asocian con la multimodalidad en varias investigaciones. Dichos enfoques y teorías son discutidos por Jewitt (2009, p. 28-39).

10. "There is a potent point to multimodality as such, namely the assertion that 'language' is just one among the resources for making meaning; and that all such resources available in one social group and its cultures at a particular moment ought to be considered as constituting one coherent domain, an integral field of nevertheless distinct resources for making meaning; all equal, potentially, in their capacity to contribute meaning to a complex semiotic entity, a text or text-like entity."

11. Expresión utilizada por Kress y van Leeuwen (2006) en su obra Gramática del Design Visual. 
y orales. Los ejemplos que aquí destacamos sirven para ilustrar la complejidad semiótica que siempre caracterizó el escenario semiótico de la humanidad.

No defendemos la competición entre los modos semióticos, sino la coocurrencia entre ellos, cada uno con sus peculiaridades y contribuciones, propiciando condiciones para entender que, en la construcción de sentidos, los modos semióticos se integran. Dicha afirmación se basa en la investigación de Araújo (2011, p. 15): "En la construcción de sentidos, los modos semióticos están integrados, lo que nos permite afirmar que todo el texto es multimodal"

Teniendo en cuenta que, para el sentido común, el modo semiótico visual está vinculado a imágenes y diversidades de colores y formas, puede parecer difícil aceptar que todo texto es multimodal, incluso el que estamos leyendo ahora. Esa resistencia puede disiparse si entendemos la idea de Dionisio $(2005$, p. 166) de que los géneros de textos escritos consisten en una capacidad informativa visual progresiva "al pasar de lo menos visualmente informativo a lo más visualmente informativo" (Énfasis añadido).

Lo que Dionisio argumenta es que un texto para ser multimodal no debe obligatoriamente estar repleto de imágenes, pues basta la existencia de esa variación de menos a más, que se da en un continuum, para que el texto sea considerado multimodal. Por lo tanto, un texto de una tesis con sus títulos en negrilla, diferentes tamaños de las fuentes tipográficas y la diagramación ya contempla esa variación de la integración de los diversos modos semióticos. Por consiguiente, es más evidente que la multimodalidad también es "el uso de varios modos semióticos en el diseño de un producto o evento semiótico" (KRESS, VAN LEEUWEN, 2001, p. 20).

\section{LITERACIDAD Y MULTILITERACIDADES}

En esta sección se discute la visión que tenemos sobre literacidad y multiliteracidades, presentando así la base que sustentará nuestro entendimiento sobre literacidad crítica y literacidad visual. Inicialmente, queremos abordar la cuestión del término literacidad, pues juzgamos importante esta observación en medio de la confusión que Cassany (2010) reconoció en los encuentros internacionales. Según este autor, existe un cambio desordenado y sin sentido entre términos como alfabetización, alfabetismo, literacidad, escritura, lectura y cultura letrada en español, tratando de significar lo mismo. Después de analizar varios de esos términos, Cassany (2010, p. 354) se une a otros autores y opta por literacidad al considerar que:

El concepto literacidad (literacy en inglés) incluye un amplio abanico de conocimientos, prácticas sociales, valores y actitudes relacionados con el uso social de los textos escritos en 
cada comunidad. En concreto, la literacidad incluye el dominio y el uso del código alfabético, la construcción receptiva y productiva de textos, el conocimiento y el uso de las funciones y los propósitos de los diferentes géneros discursivos de cada ámbito social, los roles que adoptan el lector y el autor, los valores sociales asociados con estos roles (identidad, estatus, posición social), el conocimiento que se construye en estos textos y que circula en la comunidad, la representación del mundo que transmiten, etc.

Como es posible deducir de las palabras de Cassany, la literacidad no es sólo una práctica puramente mental, sino que es también una acción social y política que concibe el texto a partir de su uso social en una comunidad. Además, para tal concepción, hay que tener en cuenta los valores sociales del autor y el lector. A esto se sumar que la concepción de Cassany va al encuentro de la semiótica social (multiliteracidades y literacidad multisemióticas) que nace justamente en el campo de los Nuevos Estudios de la Literacidad (en adelante NEL). Este campo entiende la literacidad como una práctica más allá del acto estrictamente cognitivista e individual de adquisición de habilidad y competencias, es decir, como práctica social y crítica.

En el caso de que el texto contenga lectura, escritura y oralidad, a partir de aquí sólo consideraremos la lectura, pues el corpus de nuestra investigación está limitado a la comprensión lectora. En las dos subsecciones siguientes discutiremos más detalladamente sobre la literacidad crítica y visual, teniendo como base la reflexión realizada sobre literacidad y multiliteracidades.

\section{LITERACIDAD CRÍTICA}

Hemos escogido la visión de lectura crítica y literacidad crítica de Cervetti et al (2001) para que tal visión nos guíe en la lectura de los anuncios publicitarios de este trabajo. Por eso, exponemos la diferenciación entre las dos, puesto que, para estos autores, existen claras y pertinentes diferencias entre ellas.

Esas diferencias están estructuradas en cuatro supuestos que colaboran didácticamente para el entendimiento de esa diferenciación: conocimiento, realidad, autoría y objetivos educativos. En el cuadro 1 resumimos las características principales de esos cuatro puntos dentro del enfoque de lectura crítica liberalhumanista: 
Cuadro 1. Principales características de la lectura crítica

\begin{tabular}{|l|l|}
\hline Área & Lectura Crítica \\
\hline \multirow{3}{*}{$\begin{array}{l}\text { 1. Conocimiento } \\
\text { (epistemología) }\end{array}$} & $\begin{array}{l}\text { 1. El conocimiento se adquiere a través de la experiencia sensorial del } \\
\text { mundo y por medio del pensamiento racional (decodificación). } \\
\text { 2. El significado se extrae del texto. } \\
\text { 3. Existen tres distinciones importantes: } \\
\text { a. Se distinguen hechos (objetivos) de inferencias y juicios (subjetivos) } \\
\text { bel lector. } \\
\text { b. Se distingue ciencia (lenguaje objetivo) de retórica (fantasía, } \\
\text { literatura). } \\
\text { c. Se distingue la opinión de la verdad. }\end{array}$ \\
\hline 2. Realidad (ontología) & $\begin{array}{l}\text { 1. La realidad es directamente cognoscible y por eso es un referencial } \\
\text { para la interpretación. }\end{array}$ \\
\hline 3. Autoría & $\begin{array}{l}\text { 1. La lectura crítica incluye reconocer el propósito del autor. } \\
\text { 2. El estudiante debe detectar las intenciones del autor, pues es la base } \\
\text { para los niveles más altos de interpretación textual. } \\
\text { 3. Los textos están impregnados de la intención del autor. }\end{array}$ \\
\hline $\begin{array}{l}\text { 4. Objetivo de las } \\
\text { actividades }\end{array}$ & $\begin{array}{l}\text { 1. Desarrollar los niveles superiores de habilidad de comprensión e } \\
\text { interpretación. }\end{array}$ \\
\hline
\end{tabular}

Fuente: Adaptado de Cervetti et al. (2001, en línea).

En el cuadro 1, queda claro que la lectura crítica se basa en la creencia empirista de que el mundo puede ser directamente experimentado y conocido y por eso aboga por que el lector, a través de la decodificación, puede comprender el significado "correcto" que un autor imprimió en el texto. Está claro que lo crítico es tener la capacidad superior de extraer la verdad del texto por medio del pensamiento crítico, que es el pensamiento racional que distingue hechos de inferencias y opiniones. La participación del lector es importante mientras él sea capaz cognitivamente de separar la verdad de la opinión y llegar a las intenciones del autor. La literacidad crítica implica una postura fundamentalmente diferente. Es lo que verificamos en el cuadro 2: 
Cuadro 2. Principales características de la literacidad crítica

\begin{tabular}{|l|l|}
\hline Área & Literacidad Crítica \\
\hline $\begin{array}{l}\text { 1. Conocimiento } \\
\text { (epistemología) }\end{array}$ & $\begin{array}{l}\text { 1. El conocimiento no es natural o neutro. } \\
\text { 2. El conocimiento se basa siempre en las reglas discursivas de una } \\
\text { determinada comunidad, por lo tanto, es ideológico. }\end{array}$ \\
\hline 2. Realidad (ontología) & $\begin{array}{l}\text { 1. No existe un conocimiento definitivo sobre la realidad. } \\
\text { 2. La realidad no puede ser capturada por el lenguaje. } \\
\text { 3. No se puede definir la verdad en una teoría de correspondencia con la } \\
\text { realidad, ésta debe ser comprendida en un contexto situado. }\end{array}$ \\
\hline 3. Autoría & $\begin{array}{l}\text { 1. El significado textual es siempre múltiple y discutible. } \\
\text { 2. El significado es cultural e históricamente situado. } \\
\text { 3. Se consideran las relaciones de poder en la construcción del } \\
\text { significado. }\end{array}$ \\
\hline $\begin{array}{l}\text { 4. Objetivo de las } \\
\text { actividades }\end{array}$ & $\begin{array}{l}\text { 1. Desarrollo de la conciencia crítica y transformación de la realidad de } \\
\text { opresión. }\end{array}$ \\
\hline
\end{tabular}

Fuente: Adaptado de Cervetti et al. (2001, on-line).

De acuerdo con el cuadro 2, para Cervetti et al. (2001), es evidente que la literacidad crítica es mucho más que la capacidad de decodificar o buscar la idea de un autor en el texto. En ella, el estudiante, el profesor y el material didáctico preguntan por la naturaleza de la literacidad, la conciben como práctica social y eso implica en asumir una posición en relación con el texto y la realidad. Como afirman Cervetti et al. (2001, en línea):

\begin{abstract}
Aunque existen varias versiones de literacidad crítica, ellas comparten la creencia de que la literacidad es una "práctica social y política, en lugar de un conjunto neutro de habilidades psicológicas" (Siegel; Fernández, 2000, p. 18). La literacidad crítica implica una comprensión del modo como ideología y prácticas textuales forman la representación de las realidades en los textos. ${ }^{12}$
\end{abstract}

Esta concepción crítica, según Cervetti et al. (2001), recibió la influencia de tres pensamientos que colaboran en la diferenciación de otras tradiciones de literacidad: la teoría social crítica, el posestructuralismo y la pedagogía crítica de Paulo Freire. Por cuestiones espaciales, solamente destacamos apenas la influencia de Paulo Freire en el presupuesto "Objetivos de las actividades":

12. "Although there are several versions of critical literacy, they share the belief that literacy is a "social and political practice rather than a set of neutral, psychological skills" (SIEGEL \& FERNANDEZ, 2000 , p. 18). Critical literacy involves an understanding of the way ideology and textual practices shape the representation of realities in texts." 
El objetivo pedagógico de una educación crítica era para Freire (y sigue siendo para muchos teóricos críticos) el desarrollo de la conciencia crítica. En la perspectiva de la conciencia crítica, los alumnos leen textos (y el mundo) críticamente, y van más allá de la lectura crítica de los textos para convertirse en actores contra situaciones opresivas. (CERVETTI et al., 2001, on-line) $)^{13}$

Esa visión de la literacidad crítica recogida en el cuadro 2 es la que queremos que nos guíe en esta propuesta de trabajo. Recurriremos específicamente a los puntos 3 (Autoría) y 4 (Objetivo de las actividades) del cuadro 2. Para realizar la interfaz entre literacidad crítica y la lectura de las imágenes, dedicamos la siguiente sección a discutir sobre literacidad visual.

\section{LITERACIDAD VISUAL}

Partimos de la idea de que las imágenes publicitarias pueden ir más allá de una simple función decorativa, es decir, pueden estar al servicio de la producción de sentido. Para Callow (1999), es evidente que los textos multimodales están presentes en la sociedad en general. Además, los estudiantes y los profesores pueden acceder a los materiales y las nuevas tecnologías para la producción de imágenes. La presencia de textos multimodales en la vida de los educadores y los estudiantes ya no es una novedad, según Callow (1999, p. 2):

Alumnos y profesores están muy familiarizados con el libro visual. Hay muchos más textos visuales que los alumnos encuentran diariamente - televisión, cine, radio, publicidad, outdoors, internet, juegos y programas de computadora, obras de arte como pinturas, dibujos y escultura, arquitectura, portadas de libro e ilustraciones. ${ }^{14}$

Esta presencia de las imágenes (y del audio también) no es novedosa, puesto que existe un gran incremento de ellas debido al avance y el acceso a las nuevas tecnologías. Son nuevas prácticas sociales y culturales globalizadas y localizadas. Las nuevas prácticas que interpelaron la producción de nuevos textos, como afirma Street et al. (2009, p. 200) al tratar de la aproximación entre los NEL y

13. "The pedagogical goal of a critical education was for Freire (and remains for many critical theorists) the development of critical consciousness. In critical consciousness, students read texts (and the world) critically, and they move beyond critical readings of texts to become actors against oppressive situations."

14. "Students and teachers are very familiar with the picture book. There are many more such texts that students encounter daily - television, film, radio, advertising, billboards, the internet, computer games and programs, art works such as paintings, drawings and sculpture, architecture, book covers and illustrations." 
la multimodalidad: "los textos moldean la práctica y son ellos mismos, a su vez, moldeados por la práctica"15.

En el caso de los textos que antes se ubicaban bajo el grado de la multimodalidad, principalmente textos usados en el aula, hoy son interpelados por estas nuevas prácticas sociales y culturales, cambiando todo el escenario semiótico y, por consiguiente, haciendo surgir la necesidad de las literacidades multisemióticas (ROJO, 2009, p. 105-107), entre ellas, la literacidad visual.

Así como para el modo verbal es importante el aprendizaje de las competencias y las habilidades cognitivas a fin de capacitar al sujeto para la lectura y la escritura, consideramos también importante la literacidad visual, sin dicotomías entre los dos modos, pues ambos caminan juntos. En este sentido, Callow (1999) entiende que, tanto para educadores como para observadores, el desafío es "explorar cómo estas imágenes funcionan y se construyen y cómo podemos ayudar a nuestros alumnos a hacer lo mismo" (1999, p. 2).

Con respecto a ese primer aspecto (cognitivo), destacamos el artículo de Suzanne Stokes (2002, p. 12). Al realizar una revisión de la literatura sobre literacidad visual en la enseñanza y el aprendizaje, esta autora presenta cinco conceptos de ese tipo de literacidad que engloban aspectos cognitivistas y decodificadores del signo visual: 1. Habilidad de leer, interpretar y entender informaciones visuales; 2. Aprendizaje de la habilidad de interpretar mensajes visuales y también de crearlos; 3. Grupo de competencias que ayudan a la persona a identificar e interpretar imágenes; 4 . Una fuerza para entender y mantener conceptos ligados al visual; y 5. La resignificación de las experiencias visuales pasadas para obtener significados nuevos.

El único concepto de Stokes (2002) que va más allá de la decodificación es el quinto, pues toma en cuenta no sólo la visión del autor de la imagen, sino experiencias del lector y su propia resignificación en la lectura. Sin embargo, en general, los conceptos de Stokes (2002) están marcados por una visión de literacidad visual como práctica individual de aprendizaje de habilidades y competencias para leer e interpretar imágenes. Esa visión de Stokes (2002) no es suficiente para el modelo de literacidad que este capítulo concibe a partir del modelo crítico delineado por Cervetti et al. (2001) en el Cuadro 2.

La literacidad visual insertada en la perspectiva de la literacidad crítica es la práctica que va más allá de la decodificación de los elementos visuales y de la pura descripción física del escenario visual. Según Oliveira (2006, p. 22), los pasos para lograr una literacidad visual que sea considerada crítica son: leer lo dicho,

15. "Texts shape practice and are themselves in turn shaped by practice." 
darse cuenta de lo que está omitido, evaluar las razones, percibir las intenciones, sacar conclusiones y, finalmente, actuar sobre las situaciones para la transformación de la realidad leída. Buscamos en Robert Muffoletto (2001) la propuesta de una literacidad visual marcada por la calidad de "crítica" y "reflexiva".

Conforme a la visión de Muffoletto (2001), la representación visual, sus interpretaciones y sus construcciones de sentido plantean cuestiones sobre beneficios y poder. Esa representación forma parte de un proceso social. En otras palabras, las imágenes son social e históricamente construidas.

Muffoletto (2001, en línea) entiende que "Reflexionar sobre la imagen es hacer preguntas a ella: ¿Por qué te has hecho? ¿Quién te hizo? ¿Por qué me demuestra lo que haces? ¿Quién se beneficia con tu existencia? ¿Cuál es el significado de esto? ¿Hay otra manera de representar lo que tú 're-presentas'?"16

En la perspectiva de Muffoletto (2001, en línea), tales cuestionamientos consideran "la naturaleza social-constructivista de la experiencia, significa asumir una perspectiva reflexiva y crítica, más que el sentido común." ${ }^{17}$ Para este autor, ser visualmente letrado va más allá de la capacidad de leer, decodificar, producir y codificar experiencias visuales. La literacidad visual es un proceso político que provoca en el observador y el productor preguntas sobre el sentido de la imagen. Por eso, él resume su postura definidora de literacidad visual como una postura política "preocupada por la construcción de sentido" y donde los educadores están "preocupados por las historias oficiales que son contadas para nuestros alumnos"18 (MUFFOLETTO, 2001, en línea).

Más que procesos cognitivos y decodificadores, las imágenes sirven como un proceso sociocognitivo para que los alumnos sean capaces de perfeccionar su juicio del mundo, su pensamiento crítico y creativo. Esta intención didáctica se alía con el pensamiento del New London Group, en el que participan varios investigadores de literacidad crítica y de la multimodalidad, como Kress, Gee y Kalantzis. Para ellos, el nuevo escenario multisemiótico revela la necesidad de incluir la multimodalidad en el currículo.

16. "To reflect on the image is to ask questions of it: Why were you made? Who made you? Why do you show me what you do? Who benefits from your existence? What is the meaning of this? Is there another way of representing what you 're-present '?"

17. "The social-constructivist nature of the experience, is to take a reflective and critical perspective over a passive and common-sense one."

18. "Is concerned with the construction of meaning (...) concerned with the official stories being told to our students." 


\section{ANALIZAR PARA PROPONER UN CAMINO DE ACCIÓN}

La actividad propuesta aquí surgió en el contexto de nuestras clases de español para los estudiantes brasileños, en este caso, estudiantes de español de los cursos superiores del área de Turismo del Instituto Federal do Ceará (IFCE) y de la carrera de Turismo de la Universidad Federal del Delta do Parnaíba (UFDPar). Seleccionamos cinco anuncios publicitarios aleatorios de internet para analizarlos desde la semiótica social y de la multimodalidad. Son tres anuncios en español y dos en portugués. La elección de dos anuncios en portugués se dio con el fin de establecer un diálogo con la lengua materna ${ }^{19}$, además de mostrar a nuestros alumnos brasileños que el fenómeno abordado en este artículo ocurre más allá de nuestras fronteras.

El primer anuncio analizado es de la tradicional gaseosa peruana Inca Kola, un producto fruto del orgullo industrial de Perú y muy admirado por los peruanos. Como vemos en la imagen 1 a continuación, hay un gorro andino muy común en las montañas de Perú. Este gorro se lleva incorporados unos auriculares, demostrando la unión entre lo tradicional y lo moderno, y a su vez, representando visualmente la realización de la idea de la publicidad: "Todo es posible en el país de las ideas." Tenemos el texto verbal se relacionando con el texto visual para demostrar la creatividad peruana en la producción de una gaseosa típica y original de Perú y en la unión de dos objetos distintos: un artesanal y otro industrial.

Además de ello, podemos ver como la imagen del gorro con el auricular y la gaseosa son partes del conjunto de signos motivados del anuncio, tal como pensaron Kress y van Leeuwen (2006). Tal signo revela también la presencia del sujeto productor del signo (sign-maker) dotado de poder. Él es capaz de asignar sentido a los signos, utilizando los modos semióticos disponibles y que más le convengan con el fin de atender sus intereses de representación y comunicación.

En ese caso, el sign-maker utilizó la imagen del tradicional gorro, el auricular altamente moderno y la gaseosa que es muy conocida para mostrar lo que es dicho de modo verbal. Es decir, supo unir diferentes signos, visuales y verbal, para construir y comunicar un mensaje, además de revelar la posición social del productor como

19. Las OCEM (Orientações Curriculares para o Ensino Médio) afirman lo siguiente sobre el papel de la lengua materna en el aprendizaje de la lengua extranjera: "O papel da língua materna nesse proceso é inegável. Daí que o processo de aquisição de uma outra língua mobilize tanto as questões identitárias (...). Uma vez mais, qualquer que seja a estratégia adotada, fica patente o papel crucial que tem a língua materna no processo de aprendizagem da estrangeira. " (BRASIL, 2006, p. 140-141). 
alguien que pone de relieve sus visiones sobre un producto comercial. Veamos la imagen:

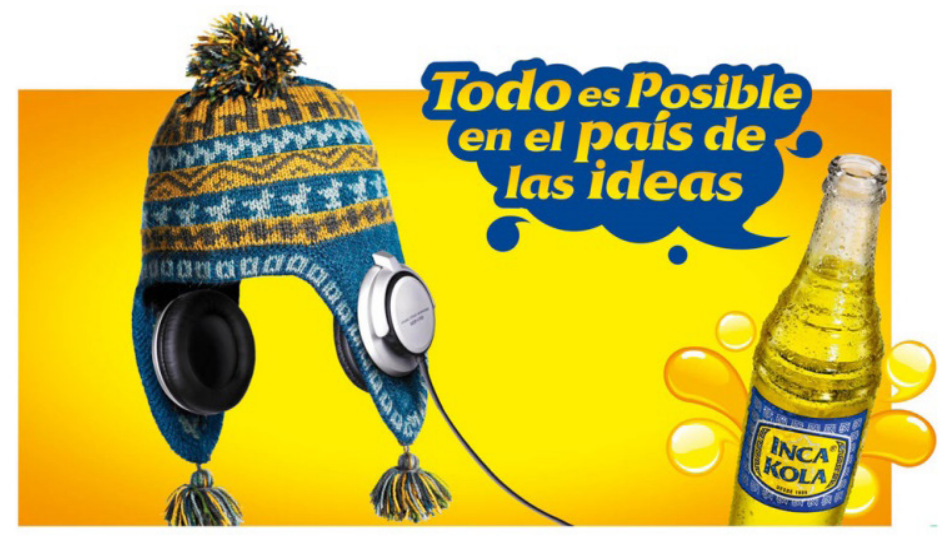

Imagen 1. Anuncio publicitario de Inca Kola

Fuente: http://eduardohuamanigarcia.blogspot.com/2012/08/la-magica-formula-de-inca-kola-inca.html

Asimismo, podemos ver que los sentidos que se originan de la lectura del anuncio de Inca Kola surgen desde el interior de una dimensión social, pues la producción del signo, su reproducción, su recepción y su circulación se dan en ambientes e interacciones sociales: del productor del signo al lector. Nada escapa del contexto social. Los sentidos atribuidos al anuncio terminan por estar iluminados por toda esta cadena social.

Por otra parte, como subrayó Kress (2010) recogido en la fundamentación teórica, al escoger unos signos se desprecia a los demás y, por lo tanto, no se produce un signo que represente toda la realidad. Nos encontramos ahí con la idea de parcialidad de la representación en la semiótica social. El interés del productor se ajustó a una parte de su mundo cultural peruano que funcionó como un principio para la selección de significantes entre varios. Por eso, el lector podrá cuestionar por qué otros signos representativos de Perú no están en el anuncio como, por ejemplo, la vicuña, las líneas de Nazca y Machu Picchu. Al tomar el principio de la parcialidad de la representación, logramos entender que el anuncio nos es absoluto en su representación visual, sin embargo, también nos es inválido.

Para reforzar lo dicho anteriormente, presentamos otros dos anuncios publicitarios de bebidas. En uno tenemos la propaganda de la tradicional cerveza colombiana Águila. El productor del signo eligió el color amarillo de la bandera 
colombiana, también es el color principal de la marca de la respectiva cerveza, lo que no se debe al azar. Él seleccionó una pareja de hinchas de la selección colombiana de fútbol vestidos con la camisa de esa selección. Los rostros del hombre y de la mujer están pintados con los tres colores de la bandera de Colombia: amarillo, azul y rojo. De esta manera, la propaganda de dicha cerveza refuerza el sentimiento de nacionalidad e identidad por parte de los colombianos.

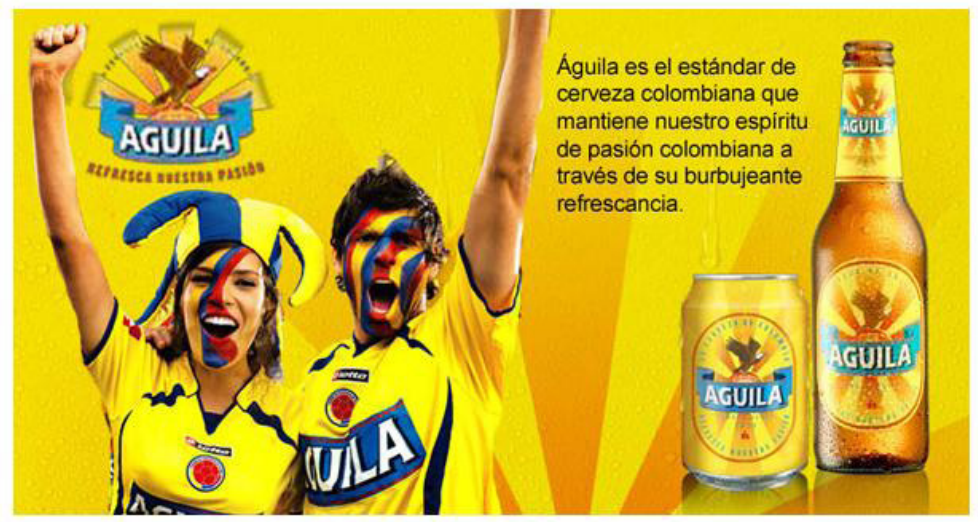

Imagen 2. Anuncio publicitario de cerveza Águila

Fuente: http://romeroads.blogspot.com/2013/05/aguila-la-cerveza-colombiana-con-100.html

Para la semiótica social y la multimodalidad, nada es arbitrario. Así como en el anuncio de Inca Kola, los signos aquí también son motivados y originados dentro de un contexto social de identidad de una nación: los colores, la camiseta de un equipo de fútbol, la pasión por este deporte expresada en el rostro de la pareja y en la fuerza de los brazos alzados. Sin dejar de lado el código verbal que en su corto párrafo, pero directo, exalta el espíritu de la pasión colombiana. Esa pasión es sostenida y reforzada por una cerveza nacional.

Otro anuncio que refuerza lo defendido anteriormente es de guaraná Antarctica, un producto originalmente de Brasil y de mucha tradición como Inca Kola. Esa publicidad anuncia una promoción para obtener camisetas exclusivas de la selección de fútbol de Brasil a través de la compra de la gaseosa Antarctica. Se utilizan los colores de la bandera de Brasil (amarillo, verde, azul y blanco), las camisetas de la selección brasileña de fútbol, asociando el sentimiento de pertenencia y apoyo a la selección de fútbol al producto anunciado, todo eso por medio de la multimodalidad. 


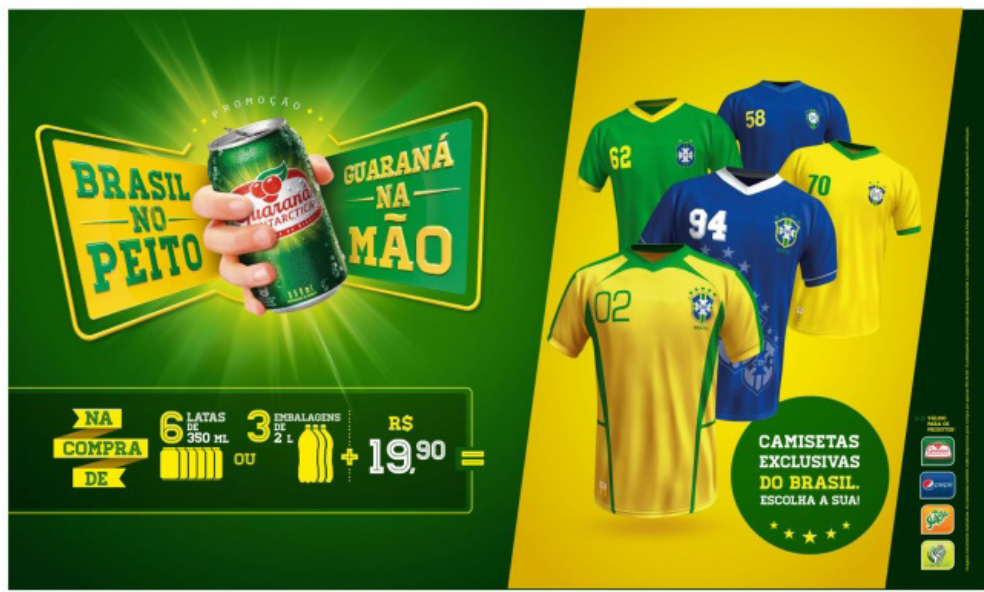

Imagen 3. Anuncio publicitario de guaraná Antarctica

Fuente: https://www.mundodomarketing.com.br/ultimas-noticias/30752/guarana-antarctica-distribui-camisas-de-mundiais-passados-em-promocao.html/

Por último, nos detenemos en un anuncio muy específico de la cerveza Águila, las Chicas Águila. Es una estrategia publicitaria de asociación de la cerveza a la mujer buscando atraer la atención de los hombres. Según la publicación colombiana especializada en economía, dinero.com ${ }^{20}$, la cerveza es la bebida más popular en Colombia. De acuerdo con esta publicación, el 62\% de los consumidores de cerveza son hombres. Por lo que esta asociación no se realiza de forma fortuita, puesto que se utiliza a la mujer como un anzuelo para atrapar al hombre, lo que confirma que el signo es motivado socialmente.

El producto cerveza está en segundo plan en el anuncio. Ya en el centro y en destaque están cuatro mujeres sonrientes denominadas Chicas Águila. La botella de cerveza no aparece por completo, solo su cuello y su cabeza en un poco de hielo, ubicada en el rincón derecho. No es difícil percibir que las cuatro chicas fueron transformadas en significante que tiene un significado.

Si nos basamos en Kress (2010, p.71), podemos decir que el interés del sign-maker en escoger la mujer y no otro tipo de signo visual revela la voluntad en asociarla a la cerveza. El interés produce la atención específica que se quiere dar a ella y a la cerveza. Esa atención específica delimita el mundo de representación que el sign-maker construye: asociación de mujer a la bebida. El significante es la imagen

20. https://www.dinero.com/economia/articulo/la-cerveza-reina-bebidas-alcoholicas-entrecolombianos/215719 
del sexo femenino y, por relación de analogía y por medio del modo semiótico adecuado (el visual), se representa visualmente un significado. El resultado es la mujer como metáfora de la felicidad, la belleza y el placer junto a un producto consumido para refrescar y acompañar momentos de divertimiento. La metáfora acaba por mostrarnos el interés del productor.

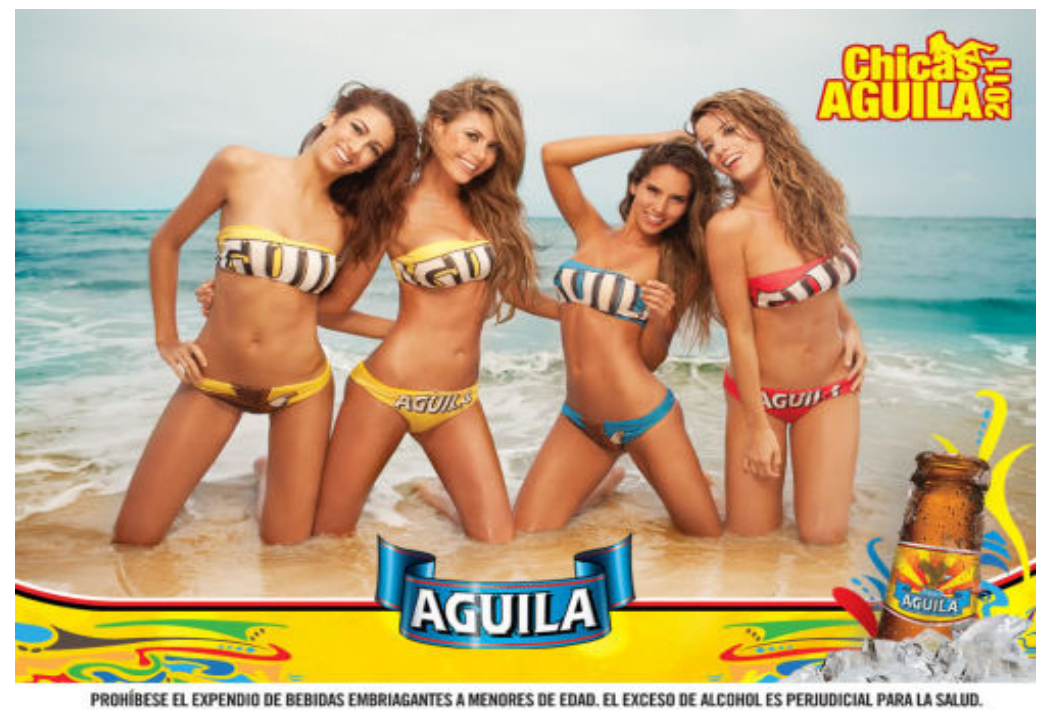

Imagen 4. Anuncio publicitario de cerveza Águila - Chicas Águila

Fuente: https://www.taringa.net/posts/imagenes/10087760/Las-chicas-aguila-belleza-colombiana.html

El mundo de representación en que el productor del signo configuró a la mujer y la cerveza demuestra la parcialidad de la representación en la semiótica social y en la multimodalidad, es decir, hay otros sentidos que representan el ser femenino y esa bebida en las diversas realidades. Este mundo escogido por el productor del signo también revela la dimensión social en la cual está inmerso el productor. Un contexto social donde una mujer delgada, bonita y joven es considerada como un producto más para ser usado para atraer la atención sobre los productos muy consumidos por hombres, y, por lo tanto, es evidente como lo social es marca constitutiva de los procesos de producción, reproducción, recepción y circulación de sentidos.

La parcialidad de la representación en la semiótica social y en la multimodalidad nos permite también cuestionar si las Chicas Aguilas representan las mujeres colombianas: La cerveza Aguila se presenta con los colores de la bandera colombiana, se muestra como un producto de pasión nacional, ćpero las mujeres de 
dicho anuncio también pueden representar la diversidad de mujeres de Colombia? Vemos como los estereotipos de mujer sirven no solo para transformarlas en objeto de deseo y placer, sino también para excluir la imagen de las mujeres que no se encuadran en modelo del anuncio.

En Brasil tenemos un anuncio publicitario de cerveza semejante al de las Chicas Águila. Es el de la cerveza Antarctica. No hay cuatro mujeres, sino una, la actriz muy conocida por los brasileños, Juliana Paes. En el anuncio, la cerveza es llamada de "BOA" (buena en español) en un bar nombrado de "BAR DA BOA" (Bar de la buena). Podemos aplicar el análisis hecho con el anuncio de las Chicas Águila a esa propaganda. Cabe señalar que la actriz Juliana Paes es el significante que visual y metafóricamente representa el significado de "BOA" y, así, se asocia, una vez más, mujer a la cerveza como objeto, "cosas" buenas para los hombres.

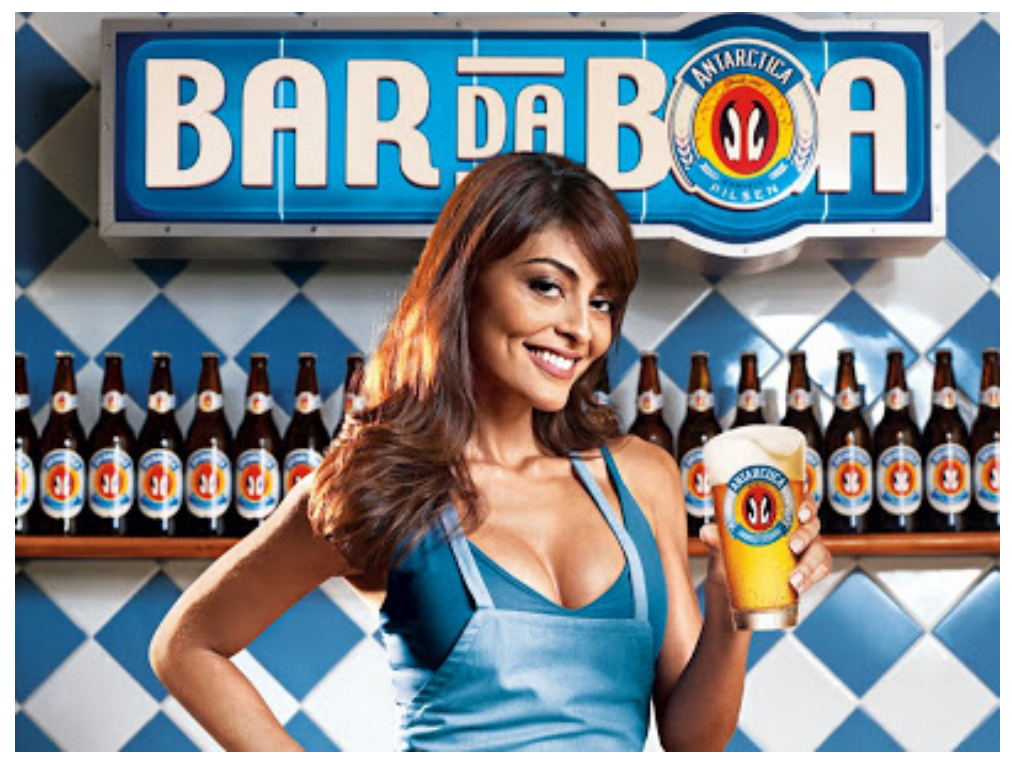

Imagen 5. Anuncio publicitario de cerveza Antarctica

Fuente: http://blogadois.blogspot.com/2008/07/bar-da-boa-novo-site-da-antrtica.html

\section{PROPUESTA DE ACTIVIDAD}

La actividad lectora de anuncios publicitarios que proponemos aquí tiene como base la literacidad como una práctica social y política, es decir, la literacidad crítica. Por eso recordamos que la formulación de dichas preguntas fuera inspirada por la visión de literacidad crítica de Cervetti et al (2001), principalmente los puntos 
3 y 4 del cuadro 2: Autoría y Objetivo de las actividades. O sea, los cuestionamientos fueron hechos para que el estudiante descubra que: 1. El sentido textual es siempre múltiple y discutible; 2. Este es cultural e históricamente situado; 3. Se consideran las relaciones de poder en la construcción del sentido; 4 . El objetivo de la actividad es desarrollar en el estudiante la conciencia crítica e invitarlo a transformar la realidad de opresión encontrada en su lectura.

Al tratarse de una lectura de la imagen, también subrayamos una vez más la visión de Muffoletto (2001) que nos inspira en los cuestionamientos: la representación visual forma parte de un proceso social, es decir, las imágenes son social e históricamente construidas, por eso, leerlas es una práctica social y política.

El profesor divide el grupo de estudiantes en equipos y le da un anuncio publicitario a cada uno de ellos. Inicialmente, los equipos observan la publicidad por unos minutos y solamente después se les entregan las preguntas. El equipo debe presentar las respuestas para todos. Dividimos las preguntas por anuncio:

\begin{tabular}{|l|}
\hline Imagen 1: Anuncio publicitario de Inca Kola \\
\hline ¿Qué producto se promociona en el anuncio? \\
\hline ¿Qué prenda de vestir se relaciona en el anuncio con la identidad de Perú? \\
\hline ¿Hay otro elemento relacionado con la identidad de ese país? \\
\hline $\begin{array}{l}\text { ¿Qué elementos visuales (color, tipografía, fotografía, formas geométricas, etc.) se } \\
\text { emplean en el anuncio para promocionar la gaseosa? }\end{array}$ \\
\hline ¿Qué quiere decir el texto Todo es posible en el país de las ideas? \\
\hline ¿Cuál es la relación entre el texto "Todo es posible en el país de las ideas" y las imágenes? \\
\hline ¿Por qué el autor del anuncio publicitario escogió los objetos presentados y no otros? \\
\hline ¿Cuál(es) es(son) la(s) idea(s) central(es) que está(n) subyacente(s) en ese anuncio? \\
\hline $\begin{array}{l}\text { Si hay alguna señal de perjuicio de clase social, raza, religión o género en el anuncio, } \\
\text { ccómo transformar esa realidad de opresión? }\end{array}$ \\
\hline Desde su carrera, ćcuál análisis específico se puede hacer sobre el anuncio? \\
\hline
\end{tabular}

Imagen 2: Anuncio publicitario de cerveza Águila

¿Qué producto se promociona en el anuncio?

¿Qué prenda de vestir se relaciona en el anuncio con la identidad de Colombia?

¿Hay otro elemento relacionado con la identidad de ese país?

¿Qué elementos visuales (color, tipografía, fotografía, formas geométricas, etc.) se emplean en el anuncio para promocionar la cerveza? 
¿Es posible afirmar que hay una exaltación de la selección Colombia en ese anuncio? ¿Por qué? ¿Qué elementos visuales y verbales respaldan tu repuesta?

¿Qué quiere decir el texto "Águila es el estándar de cerveza colombiana que mantiene nuestro espíritu de pasión colombiana a través de su burbujeante refrescancia"?

¿Cuál es la relación entre el texto "Águila es el estándar de cerveza colombiana que mantiene nuestro espíritu de pasión colombiana a través de su burbujeante refrescancia" y las imágenes?

¿Por qué el autor del anuncio publicitario escogió los objetos presentados y no otros? ¿Cuál(es) es(son) la(s) idea(s) central(es) que está(n) subyacente(s) en ese anuncio? Si hay alguna señal de perjuicio de clase social, raza, religión o género en el anuncio, ¿cómo transformar esa realidad de opresión?

Desde su carrera, ccuál análisis específico se puede hacer sobre el anuncio?

\begin{tabular}{|l|}
\hline Imagen 3: Anuncio publicitario de cerveza Águila - Chicas Águila \\
\hline ¿Qué producto se promociona en el anuncio? ¿Qué imagen te permite contestar esta \\
pregunta? \\
\hline ¿Qué prenda de vestir aparece en el anuncio? \\
\hline ¿Por qué se escogió esta prenda para el anuncio y no otra? \\
\hline ¿Qué elementos visuales (color, tipografía, fotografía, formas geométricas, etc.) se \\
emplean en el anuncio emplea para promocionar la cerveza? \\
\hline Si el anuncio es de una cerveza, cpor qué las mujeres ocupan el centro del primer anuncio? \\
\hline ¿Por qué el autor del anuncio publicitario escogió mujeres y no hombres? \\
\hline ¿Cuál(es) es(son) la(s) idea(s) central(es) que está(n) subyacente(s) en ese anuncio? \\
\hline $\begin{array}{l}\text { Si hay alguna señal de perjuicio de clase social, raza, religión o género en el anuncio, } \\
\text { ¿cómo transformar esa realidad de opresión? }\end{array}$ \\
\hline Desde su carrera, ċcuál análisis específico se puede hacer sobre el anuncio? \\
\hline
\end{tabular}

Por último, es importante señalar que: 1 . Las distintas carreras universitarias atendidas en este trabajo demandan puntos de vista particulares sobre los anuncios analizados. Como las preguntas de lectura propuestas son generales, se puede añadir, en la aplicación de la propuesta, preguntas originadas a partir de las especificidades de la carrera de los alumnos; 2. Estas actividades fueron diseñadas para estudiantes brasileños de ELE, nivel intermediario, pero, creemos que pueden ser adaptadas a otros públicos y niveles de competencia lingüística, pero es necesario que el profesor presente, obviamente, sus debidas mudanzas para garantizar el éxito en el 
aprendizaje del alumnado, tomando en consideración las necesidades y los objetivos de aprendizaje del determinado grupo de aprendientes.

\section{CONSIDERACIONES FINALES}

¿Qué clase de lectores queremos formar en nuestras clases de español como lengua extranjera para fines específicos? Proponer actividades de lectura que abarquen solamente el texto verbal, y que se detengan en la decodificación del código verbal y en la búsqueda de las intenciones del autor es una actitud que no contempla los desafíos y la complejidad del mundo en el cual viven nuestros estudiantes.

El mundo de la lectura ya no es solamente verbal. El ser humano siempre ha producido las imágenes, no obstante, hoy las utilizamos con más frecuencia. Y no solo las leemos, como las producimos en diversos ambientes, desde el hogar hasta la escuela, la calle, la universidad. Las herramientas de producción de imágenes son más accesibles que antes. Y nuestros estudiantes acuden a nuestras clases influenciados por tal contexto. Esta situación actual no se ha de despreciar, puesto que leer imágenes no consiste en una simple moda, sino, más bien, en una necesidad.

Hemos defendido en las líneas anteriores una propuesta de lectura que ofrezca a nuestro alumnado la oportunidad de formación de lectores críticos y transformadores de la realidad. Esto se da considerando que la lectura es una práctica social y política con sus diversas implicaciones: 1 . Leer no es solo decodificar; 2 . El conocimiento no es natural o neutro, sino ideológico y, por eso, hay que buscar la materialización de esta ideología en el texto; 3 . No se puede definir la verdad en una teoría de correspondencia con la realidad, esta debe ser comprendida en un contexto determinado, de ahí la necesidad del reconocimiento de la dimensión social en la producción del signo visual y verbal ${ }_{i} 4$. El significado textual es siempre múltiple y discutible, por eso la necesidad de reconocer la parcialidad de la representación de los signos; 5 . El significado es cultural e históricamente situado; 6 . Se consideran las relaciones de poder en la construcción del significado; y 7 . Leer también es actuar en la realidad leída.

Somos conscientes de que este trabajo no agota las innúmeras propuestas de lecturas en clases de español como lengua extranjera para fines específicos, por lo que nuestro planteamiento se sumará a muchos otros. Asimismo, tampoco consideramos que éste sea el mejor, sino que es una apuesta para ser probada y reformulada siempre que sea necesario. 


\section{REFERENCIAS}

ALMEIDA, D. B. L. de. (2009). Do texto às imagens: as novas fronteiras do letramento visual. In: PEREIRA, R. Gi ROCA, P. (orgs.). Linguistica aplicada: um caminho com diferentes acessos. São Paulo: Editora Contexto: 173-202.

ARAÚJO, A. D. (2011). Gêneros multimodais: mapeando pesquisas no Brasil. Linguagem em Foco. Fortaleza: EDUECE, 8(1): 13-23.

BRASIL. Orientações Curriculares para o Ensino Médio - Linguagens, códigos e suas tecnologias. Brasília: Ministério da Educação, SEB/MEC, 2006, vol. 1.

CALLOW, J. (1999). Reading the visual: An introduction. Image matters - Visual texts in the classroom. Newtown (Austrália): Primary English Teaching Association:1-13.

CASSANY, D. CASTELLÀ, J. M. (2010). Aproximación a la literacidad crítica. Perspectiva. Florianópolis, 28(2): 353-374, jul/dez.

CERVETTI et al. (2001). A tale of differences: comparing the traditions, perspectives, and educational goals of critical reading and critical literacy. Reading Online, 4(9). Disponible en: <http://www.readingonline.org/articles/artindex.asp?HREF/ articles/cervetti/index.html> Consultado el 13 may. 2011.

DEL RÍO PEREDA, P. (1996). Psicología de los medios de comunicación: hacia el diseño sociocultural en comunicación audiovisual, Editorial Síntesis, Madrid, 431p.

DIONÍSIO, A. P. (2005). Gêneros multimodais e multiletramentos. In: KARWOSKI, A. M. GAYDECZKA, B; BRITO, K. S. (orgs.). Gêneros textuais: Reflexões e ensino. Rio de Janeiro: Ed. Lucerna: 159-177.

HALLIDAY, M. A. K. (1978). Language as Social Semiotic: The Social Interpretation of Language and Meaning. London: Edward Arnold.

HODGE, R. I. V. KRESS, G. R. (1988). Social Semiotics. Cambridge: Polity Press.

JEWITT, C. (2009). An introduction to multimodality. In: JEWITT, C. The Routledge Handbook of Multimodal Analysis. London and New York: Routledge, 214p. 
KRESS, G. (2005). Alfabetismo y multimodalidad. Un marco teórico. En G. Kress, El alfabetismo en la era de los nuevos medios de comunicación. Granada, España: Ediciones Aljibe, p. 49-82, 2005.

KRESS, G. (2010). A social-semiotic theory of multimodality. In: Multimodality - A Social semiotic approach to contemporary communication. London and New York: Routlegde, 170p.

KRESS, G. (2011). 'Partnerships in research': multimodality and ethnography. In: Qualitative Research. London: June: 227-237.

KRESS, G. van LEEUWEN, T. (2006). Reading images: the Grammar of visual design. London: Routlegde.

KRESS, G. van LEEUWEN, T. (2001). Multimodal Discourse: The Modes and Media of Contemporary Communication. London: Edward Arnold.

MUFFOLETTO, R. (2001). An Inquiry into the nature of Uncle Joe's representation and meaning. Reading Online, 8(4). Disponible en: < http://www.readingonline.org/ newliteracies/muffoletto/index.html > Consultado en: 12 oct. 2011.

OLIVEIRA, S. (2006). Texto visual e leitura crítica: o dito, o omitido, o sugerido. Linguagem \& Ensino, 9(1): 15-39.

OVIEDO, G. L. (2004). LA definición del concepto de percepción en psicología con base en la teoría Gestalt. Revista de Estudios Sociales, no. 18, agosto de 2004, 89-96.

ROJO, R. (2009). Letramentos múltiplos, escola e inclusão social. São Paulo: Parábola Editorial.

SAUSSURE, F. (2006). Curso de lingüística geral. São Paulo: Cultrix. Traducción de Antônio Chelini, José Paulo Paes y lzidoro Blikstein. Edición consultado de 2006, disponible en https://edisciplinas.usp.br/pluginfile.php/4622783/mod resource/content/1/Saussure16CursoDeLinguisticaGeral.pdf Consultado el 10 oct. 2019.

STOKES, S. (2002). Visual literacy in teaching and learning: A literature perspective. Electronic Journal for the Integration of Technology in Education. Pocatello (EUA), 1(1): 10-19. Disponible en: <http://ejite.isu.edu/Volume1, No1/pdfs/stokes.pdf > Consultado el 12 oct. 2011. 
STREET et al. (2009). Multimodality and new literacy studies. In: JEWITT, C. (Ed.) The Routledge Handbook of Multimodal Analysis. London/New York: Routledge: 191-200.

van LEEUWEN, T. (2011). Multimodality. In: SIMPSON, J. (Editor). The Routledge Handbook of Applied Linguistics. London and New York: Routledge, 732p.

Recebido: 17/1/2020

Aceito: 26/6/2020

Publicado: 22/7/2020 